\title{
REIVINDICACIÓN DE LAS REPRESENTACIONES FEMENINAS EN EL AUDIOVISUAL ESPAÑOL: ESTUDIO DE UNA DÉCADA DE ARQUETIPOS DE MUJERES EN LOS PREMIOS GOYA
}

\section{DEMANDS OF FEMALE REPRESENTATIONS IN SPANISH AUDIOVISUALS: A STUDY OF A DECADE OF ARCHETYPES OF WOMEN IN THE GOYA AWARDS}

Paula Meliveo Nogues. Universidad de Málaga. España. paulameliveo@uma.es

Carmen Cristófol-Rodríguez. Universidad de Málaga. España. carcrir@uma.es

Cómo citar el artículo:

Meliveo Nogues, P. y Cristófol-Rodríguez, C. (2021). Reivindicación de las representaciones femeninas en el audiovisual español: estudio de una década de arquetipos de mujeres en los premios Goya. Revista de Ciencias de la Comunicación e Información, Vol. 26, 39-57.

http://doi.org/10.35742/rcci.2021.26.e138

\section{RESUMEN}

Los Premios Goya se han convertido en los últimos años en escenario de reivindicaciones del sector cinematográfico español por la repercusión mediática de su gala. A partir una triangulación metodológica que aplica el estudio del caso, el análisis de contenido y entrevistas en profundidad, esta investigación propone una nueva categorización de arquetipos femeninos en el cine español actual, prueba la existencia de la discriminación de género a través de la representación estereotipada de la mujer, y analiza si estos arquetipos se perpetúan y difunden también a través de las revistas femeninas de alta gama y suplementos dominicales. La conclusión principal de este estudio establece que la creación de una ley proteccionista para acabar con esta marginación es imprescindible y una deuda del pasado histórico-político de España

PALABRAS CLAVE: Cine español, Premios Goya, mujeres, arquetipos, género, reivindicación

\section{ABSTRACT}

In recent years, the Goya Awards have become a stage for the claims of the Spanish film sector due to the media coverage of the gala. Based on a methodological triangulation that applies case studies, content analysis and in-depth interviews, this research 
proposes a new categorisation of female archetypes in current Spanish cinema, proves the existence of gender discrimination through the stereotypical representation of women, and analyses whether these archetypes are also perpetuated and disseminated through high-end women's magazines and Sunday supplements. The main conclusion of this study is that the creation of a protectionist law to put an end to this marginalisation is essential and a debt from Spain's historical and political past.

Keywords: Spanish Cinema, Goya Awards, women, gender stereotypes, demands

\section{INTRODUCCIÓN}

\subsection{Estado de la cuestión. Arquetipos femeninos y actrices en el cine español}

La situación de las actrices en la industria cinematográfica española ha permanecido estancada en la interpretación de personajes supeditados a los roles masculinos (Tello, 2016). De esto se deriva que las actrices más valoradas por la Academia de Cine de España entre 2010 y 2020 hayan sido galardonadas con el Premio Goya en las tres categorías de protagonista, secundaria y revelación, interpretando en su mayoría, personajes estigmatizados por esa discriminación (Academia de Cine, 2020). Los antecedentes históricos de la marginación que ha afectado en la última década a personajes de mujer y actrices los encontramos en los mecanismos de socialización franquista como los que suponen la producción cultural y cinematográfica, que han logrado transmitirse hasta llegar a la sociedad y las producciones de ficción de estos últimos diez años. Así lo recoge el autor Javier Jurado en un estudio sobre los roles de género en el cine patrio entre 1940 y 1959:

durante cuarenta años, el adoctrinamiento nacional-católico en torno a la moral y los roles de género tuvieron un alcance pocas veces reconocido hasta tiempos muy recientes. Es por ello imprescindible fijarse en los modelos establecidos en los primeros años de la dictadura para comprender la evolución y la adaptación de los mismos a las estrategias de legitimación tanto de la dictadura como del orden social preconizado por la misma (Jurado, 2017, p. 132).

La Guerra Civil y la Segunda Guerra Mundial habían creado en España la necesidad de reconstruir el país desde el crecimiento demográfico que propiciaría el aumento de la productividad y la mejora económica. La maternidad y el cuidado de los hijos se convirtieron en algo prioritario para el estado, que contó con el apoyo de la moral católica para lograr que esta ideología penetrara en la mentalidad de hombres y mujeres. La mujer se convertía en una menor de edad bajo la tutela de su padre o su marido. El estado en nombre del cristianismo y la moral que creó para la época fiscalizó el rol de la mujer en la sociedad y se encargó que su comportamiento fuese el más adecuado para la repoblación de España (De Riquer, 2013, p. 293). El cine durante la dictadura representó los roles de la mujer que la ideología de aquel momento inculcaba. También los del hombre, lo que reforzó aún más la desigualdad. Ya en los años sesenta, la influencia extranjera y un paulatino aperturismo provocan que la censura se relaje. En 1964 La tía Tula (Miguel Picazo), advierte sobre la presión a la que la mujer se ve sometida (Rodríguez Sánchez, 2011, p. 133-134). Como señala Jurado, estos roles se han transmitido a las generaciones actuales, siendo 


\section{REIVINDICACIÓN DE LAS REPRESENTACIONES FEMENINAS EN EL AUDIOVISUAL ESPAÑOL: ESTUDIO DE UNA DÉCADA DE ARQUETIPOS DE MUJERES EN LOS PREMIOS GOYA}

perceptibles tanto en la sociedad como en las producciones cinematográficas. Sin embargo, "es difícil encontrar en la cartelera actual a una mujer autónoma y comprometida socialmente, preocupada por sí misma, interesada por la cultura, los viajes o la actualidad con una vida sana y plena" (Gordillo, 2010, p 101). Como indica la autora.............. en ....................., en ciertos nombramientos de cargos culturales durante la década de los sesenta, se evidencia el control del dictador de los mensajes cinematográficos en pro del adoctrinamiento masivo de la población española, y la consolidación de los fines de la ideología nacionalcatolicista:

José María García Escudero, coronel del cuerpo jurídico del Ejército del Aire, crítico cinematográfico, escritor y participante en las Conversaciones de Salamanca, fue elegido por el ministro de Información y Turismo para ocupar el cargo de Director General de Cinematografía y Teatro. García Escudero ejerció su cargo entre 1962 y 1967, iniciando una época de cambios desde el punto de vista fílmico e industrial. desde el comienzo García Escudero pretendió realizar una revolución personalizada caracterizada por la racionalización del mercado, sustituyendo las estructuras del antiguo cine y apostando por una nueva generación de cineastas más atentos a las potencialidades culturales del cinematógrafo (Sánchez Rodríguez, 2013, p. 71)

La ausencia de mujeres mayores de cincuenta años en papeles protagónicos o de cierta relevancia es una asignatura pendiente. Las actrices que pasan de los sesenta y cinco años lo tienen incluso complicado para interpretar secundarios o personajes de reparto (2010, p. 97). Como arquetipos recurrentes que el cine español asigna a actrices mayores reconoce los siguientes: "la abuela enferma, la vieja bruja, la abuela coraje, la abuela alegre, la madura enamorada y la abuela infiel" (2010, p.103-116). Interpretando el estereotipo de "la madura enamorada" encontramos a Adelfa Calvo, premiada por la Academia de Cine en 2018 con el Premio Goya a Mejor Actriz de Reparto, quien se reconoce en desigualdad con respecto a sus compañeros de profesión. Su personaje no aparecía escrito en el guion tal y como apareció en pantalla. La galardonada comenta que la creación del personaje no corre a cargo sólo del guionista y del director, sino también del intérprete. En su caso dio un paso más dignificando un personaje concebido por un hombre (Javier Cercas), como una mujer pasiva e irrelevante:

En principio mi personaje no tenía nombre, y yo creo que la dignificamos mucho poniéndole nombre. Al final acabó llamándose Lola. Esto creo que es bastante importante, que un personaje que se llame 'la portera' que acabe teniendo identidad es algo destacable. Yo quise empoderarla mucho [...] Esto fue posible gracias a que el director cambió muchas cosas según sugerencias que le fui haciendo (Comunicación personal, 29 de octubre de 2020).

Sin embargo, como comenta la actriz, no todos los directores son receptivos a cambiar características de personajes que indica el guión. El rol de madre, por herencia del cine producido durante la dictadura es uno de los más recurrentes. Como recoge la autora Virginia Guarinos en su clasificación de arquetipos de mujeres en las producciones del siglo XXI, 4 de 17 arquetipos de mujer son madres, estableciendo las subcategorías de: "mater amabilis" (amorosa y feliz, cuya vida se focaliza en el cuidado de sus hijos y su marido), "mater dolorosa" (sufridora), "madre castradora" (sin ternura, dominante) y "madrastra" (enemiga de sus hijastros) (2008: 106-108). La autora Kathlyn Everly considera que en el cine de Almodóvar es significativo que no 
relegue a las actrices a representar roles de madre, hermana o hija dotando sus películas de variedad de personajes para mujer: "Lo que sí logra Almodóvar en gran medida es representar en sus filmes una variedad de personajes femeninos que en algún sentido indica que las mujeres somos individuos y no siempre cabemos en unas categorías preestablecidas por la sociedad, como madre, hermana o hija" (Everly, 2016: 183). Según el director, el personaje por el que Julieta Serrano recoge el Goya a Mejor Actriz de Reparto 2020 "no es una madre sin más, es fuerte, como todas las de su generación que levantaron España tras la posguerra" (Comunicación personal, 26 de enero de 2020). Otro de los problemas que afecta a la arquetipia, es que la mayoría de las películas están dirigidas por hombres: " Las mujeres otorgan el protagonismo a las mujeres de manera más habitual, alcanzando casi el $50 \%$ de las producciones realizadas por las directoras, frente al $80 \%$ del protagonismo masculino del que adolecen las películas dirigidas por varones “ (Tello, 2016).

Cabe reseñar el estudio de Sánchez Rodríguez (2018) que expone cómo el cine español del franquismo (1939-1975) parecía haber caído en el olvido, aunque señala que al menos, en el ámbito académico si existen investigaciones en este contexto La autora propone un estudio de dicha época con visión femenina, estudiando a las actrices que formaron parte de aquel cine. Se observa cómo un grupo de mujeres pioneras consiguió hacerse un hueco en el medio como directoras, productoras o guionistas, aunque las que mayor visibilidad tenían, eran evidentemente sean las actrices. Este estudio propone una propuesta de perfiles profesionales femeninos.

La exclusión de mujeres de la dirección y la producción se explica también ya que el cine refuerza su invisibilidad simbólica en la representación: "Una de las estrategias es la de no hacerlas protagonistas de las historias que se cuentan, ubicándolas como acompañantes o asistentes de los deseos de los hombres. Además, los personajes femeninos sufren un déficit de representación porque poseen caracteres malhumorados y poco simpáticos; y se las atribuyen los valores de género más tradicionales" (Bernárdez-Rodal y Padilla-Castillo, 2018: 1261).

\subsection{Premios Goya y reivindicaciones: personajes para mujeres}

Tras el nacimiento de la Academia de Cine el 12 de noviembre de 1985, la creación de unos premios nacionales que promocionaran las producciones españolas, un censo profesional y la creación de una Escuela Oficial de Cinematografía eran objetivos inminentes. La primera gala de los Premios Goya se celebró el 16 de marzo de 1987, premiando 16 categorías que fueron aumentando con el transcurso del tiempo (Pérez Granados, 2006: 19). A pesar del éxito de estos premios, se reducen a tres las publicaciones académicas que los analizan. $Y$ aunque ninguna de ellas trata el tema de las actrices más valoradas por estos galardones ni los personajes que les han conducido a recoger la estatuilla como este estudio, han puesto el foco en aspectos como su estrategia de marketing (Castelló y Jover, 2018), su cobertura informativa (Vizcaíno-Laorga, Montes y de la Torre, 2017), y los reportajes publicados entre 2005 y 2014 en Elpaís.com (Freixa, 2015).

Por su naturaleza promocional esta gala de premios retransmitida en directo por Televisión Española es una potente plataforma de difusión no sólo de productos cinematográficos consumibles, sino de mensajes a la sociedad. Por ello se ha 


\section{REIVINDICACIÓN DE LAS REPRESENTACIONES FEMENINAS EN EL AUDIOVISUAL ESPAÑOL: ESTUDIO DE UNA DÉCADA DE ARQUETIPOS DE MUJERES EN LOS PREMIOS GOYA}

convertido en ocasiones en el escenario de reivindicaciones sociales, económicas, artísticas, feministas o incluso climáticas (Meliveo, 2020, observaciones de campo). Cronológicamente las causas que se han reivindicado durante la gala de los Goya o la convocatoria en la alfombra roja y están documentadas por la Academia son: 1998, el terrorismo; 2003, la invasión de Irak por Estados Unidos y sus aliados; 2004, ETA y la película La pelota vasca. La piel contra la piedra; 2008, la disolución definitiva de la Conferencia Episcopal; 2009, el peligro del Opus Dei; 2011, Ley Sinde; 2011, las medidas antipiratería promovidas por el PSOE; 2012, protección de las víctimas del terrorismo y la inhabilitación del juez Garzón; 2013, la situación laboral de las actrices y de los hospitales públicos (Academia de Cine, 2020).

Desde 2013 la página web oficial de la Academia de Cine de España no actualiza ningún acto reivindicativo más en la historia de sus los Premios Goya. Como nos comenta la intérprete ganadora del Goya en 2018 a la Mejor Actriz de Reparto por la película El autor, Adelfa Calvo, en la ceremonia de ese mismo año tuvieron lugar acciones reivindicativas por la igualdad, con una importante repercusión en prensa y en redes sociales. Compañeras de la misma asistente a la gala portaron un abanico con el lema "Más mujeres" y declararon en prensa la necesidad de más personajes femeninos de mayor complejidad narrativa y variedad de perfiles (Comunicación personal, 29 de octubre de 2020).

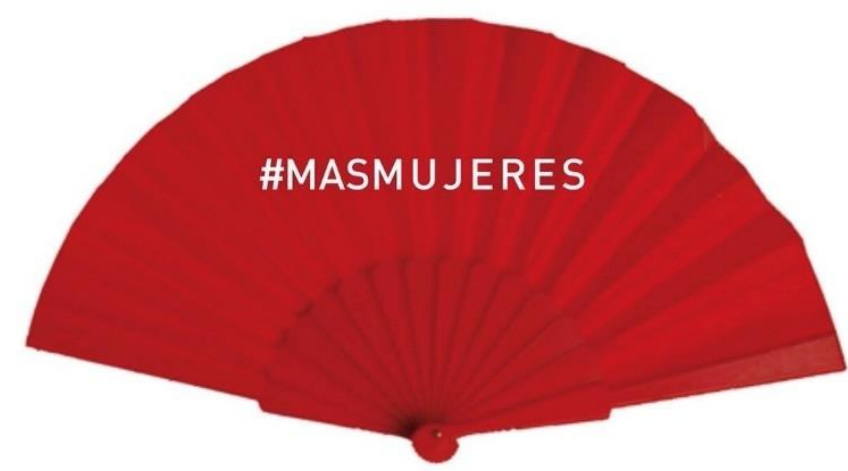

Imagen. 1. Abanico \#MásMujeres (Academia de Cine, 2020)

El poder de difusión y alcance de los Premios Goya son contemplados por los trabajadores de la industria audiovisual en España para hacer visible causas que consideran justas, como confirma Adelfa Calvo, quien añade que este movimiento por la igualdad fue importado de Estados Unidos: "A partir de 2017 cuando ocurrió todo aquello de la campaña del Me Too en América, aunque nosotras nos sumamos un poco más tarde, el mensaje en contra de los abusos sexuales de la mujer y de la mayor presencia femenina en el cine ya lo llevábamos todas en la cabeza, y aprovechamos la oportunidad que te da una plataforma como los Premios Goya para decir muchas cosas que no podemos decir, y alzamos la voz" (Comunicación personal, 30 de octubre de 2020).

Las acciones reivindicativas de las actrices asistentes y premiadas en la edición de Premios Goya 2017 y 2018, y otros certámenes cinematográficos de 2018 como el Festival de Málaga, estuvieron impulsadas y organizadas por CIMA (Asociación de Mujeres Cineastas y de Medios Audiovisuales). Así nos lo confirma Isabel Sevilla, una de las coordinadoras de esta asociación, especificando algunos de los motivos por los 
que se fundó esta institución: "Los papeles asignados a las mujeres en la ficción están supeditados a los hombres, tienen menos visibilidad y presencia lo que condiciona los personajes que las compañeras reciben. De esos papeles nacen referentes para la sociedad que no sólo no responden a la realidad, sino que pueden ser contraproducentes para el deseable objetivo de igualdad. "(Comunicación personal, 30 de octubre de 2020).

Desde el origen de esta asociación en 2006, la lucha por la inclusión de personajes femeninos que no estén estereotipados en las producciones cinematográficas ha sido una constante. Como confirma la actriz Julieta Serrano, Goya a la Mejor Actriz de Reparto 2020, "En la actualidad sigue siendo una tendencia muy arraigada, se escriben personajes para mujeres en función de otros personajes centrales que interpretan hombres, y se les vincula con el poder " (Meliveo, 2020, observaciones de campo).

\subsection{Revistas femeninas}

Las revistas femeninas han sido desde sus inicios un instrumento de referencia y de reivindicación para la mujer, tal y como afirma Marrades (1978) sobre la Pensadora Gaditana, primera referencia feminista de la que se tiene conocimiento "La Pensadora fue una anticipación original del feminismo español a la vez que un feliz inicio de prensa femenina", aunque sin embargo, no tuyo grandes seguidores. Paradójicamente, tal y como refleja Martín (2017) en su tesis doctoral, la mayoría de las publicaciones que fueron surgiendo se dedicaban a temas de adoctrinamiento femenino como la educación, la educación moral y la moda. Por lo que históricamente, según Sánchez Hernández (2010), se ha distinguido entre revista o prensa femenina y revista o prensa para mujeres: entre las primeras se encuentran aquellas cuya temática se refiere al hogar, la moda o la belleza y las segundas se dirigen a mujeres con otro tipo de intereses, entre las que cabría destacar las de corte feminista.

Sin embargo, en la actualidad, las revistas femeninas de alta gama se definen como "aquella dirigida a una mujer de entre 25 y 45 años de edad de nivel social medio-alto, cuyos contenidos se centran casi exclusivamente en los sectores de la moda y la belleza" Cristófol y Méndiz (2010).

Con lo que, desde el inicio de este tipo de publicaciones, la mujer ha visto un reflejo de sus aspiraciones todo el contenido de las mismas y por ende a partir de ellos podían deducirse los estereotipos esperados para ellas.

Teniendo en cuenta las temáticas de las revistas para las mujeres, es más evidente el estudio de los estereotipos de la mujer reflejada en ellas. Almansa y Gómez (2017) distinguen entre los estereotipos reflejados en la publicidad y los reflejados en los contenidos entre 2007 y 2014 . En los contenidos aparece principalmente el rol de la mujer chic y glamourosa; Blanco García y Leoz (2010), afirman que "Los elementos visuales utilizados en la composición de las portadas proponen modelos femeninos estereotipados y limitados", y que el rol de personajes más repetido en portadas es el de actriz. 
REIVINDICACIÓN DE LAS REPRESENTACIONES FEMENINAS EN EL AUDIOVISUAL ESPAÑOL: ESTUDIO DE UNA DÉCADA DE ARQUETIPOS DE MUJERES EN LOS PREMIOS GOYA

\section{OBJETIVOS}

Los objetivos planteados en la presente investigación son:

1) Establecer las categorías de estereotipos femeninos representados por las actrices más valoradas por la Academia de Cine entre 2010 y 2020;

2) Analizar los arquetipos femeninos interpretados por las actrices Premiadas con un Goya entre 2010 y 2020

3) Estudiar si existe discriminación de género en la concepción de esos arquetipos y las consecuencias que se derivan de esta forma de crear personajes para mujeres

4) Analizar el reflejo de dichos arquetipos en la prensa femenina (revistas femeninas de alta gama y suplementos dominicales dedicados a la mujer) como una forma de perpetuar esta representación discriminatoria de la mujer

\section{METODOLOGÍA}

La metodología utilizada para llevar a cabo esta investigación ha sido la triangulación metodológica. Para García et al., la triangulación es una estrategia metodológica, en la que confluyen diferentes métodos para el estudio de un mismo fenómeno.

Por un lado se ha llevado a cabo un estudio de caso, que para Martínez Carazo (2011) se define como una "herramienta valiosa de investigación, y su mayor fortaleza radica en que a través del mismo se mide y registra la conducta de las personas involucradas en el fenómeno estudiado", seguidamente se ha realizado un análisis de contenido para extraer "estructuras y modelos (...)basados en la deducción" (Bardín, 1991) y como cierre de esta investigación se han llevado a cabo diversas entrevistas en profundidad, entendidas las mismas como instrumentos de investigación "flexibles y dinámicos". (Díaz et al, 2013)

Por tanto, para responder a los objetivos planteados, se ha llevado a cabo un estudio del caso de los personajes femeninos galardonados en los Premios Goya en las categorías protagonista femenino, reparto femenino y novel femenino entre 2010 y 2020. Esta muestra de 33 personajes femeninos ha sido clasificada según los estereotipos establecidos por Guarinos (2008) y Planes (2010), y reelaborada a partir de los arquetipos encontrados tras realizar la presente investigación.

A continuación, se ha llevado a cabo un análisis de contenido de las revistas femeninas de alta gama y de los suplementos dominicales dedicados a la mujer en los que han aparecido estas actrices galardonadas, identificando en cada caso si el estereotipo representado, se hallaba reflejado en dicha publicación. Se han analizado todas las publicaciones que contenían el nombre de la actriz galardonada un año antes y un año después de ser premiada con galardón (Ej. Lola Dueñas, premiada en 2010, se ha buscado desde el 1 de enero de 2009 hasta el 31 de diciembre de 2011), a excepción de las premiadas en 2020, que se ha analizado únicamente hasta finales de 2020, por las limitaciones propias de la investigación.

Las publicaciones femeninas escogidas, has sido estas categorías por ser las de mayor penetración entre el género femenino según el Estudio General de Medios de 2020. Las revistas de alta gama según Cristófol y Méndiz (2015) y que han sido 
analizadas son Cosmopolitan, Elle, Glamour, Marie Claire, Telva y Vogue y los dos suplementos dominicales existentes en el mercado actual S Moda y Mujer Hoy. La búsqueda se ha llevado a cabo a través de la hemeroteca virtual Mynews.

Como cierre de esta triangulación, se han llevado a cabo entrevistas personales a través de preguntas abiertas a profesionales galardonados por la Academia de Cine en el período estudiado: Julieta Serrano (Premio Goya a Mejor Actriz de Reparto 2020), Adelfa Calvo (Premio Goya a Mejor Actriz de Reparto 2018) y Pedro Almodóvar (Premio Goya a Mejor Dirección, Guión Original y Película 2020). Para completar la visión, también se ha entrevistado a Isabel Sevilla coordinadora de CIMA (Asociación de Mujeres Cineastas y de Medios Audiovisuales). En el caso de Adelfa Calvo e Isabel Sevilla sus entrevistas se realizaron a través del teléfono y audios de whatsApp. En el caso de Julieta Serrano y Pedro Almodóvar de forma presencial en el backstage de los Premios Goya 2020 durante la celebración de la gala, el 26 de enero de 2020.

\section{DISCUSIÓN}

Guarinos establece los siguientes arquetipos femeninos en el cine español: "la chica buena, el ángel, la virgen, la beata, la chica mala, la guerrera, la femme fatale, la mater amabilis, la mater dolorosa, la madre castradora, la madrastra, la madre del monstruo, la madre sin hijos, la Cenicienta, la turris eburnea, la reina negra/bruja/viuda negra, la villana, la superheroína y la dominatrix" (2008, pp. 115-118). Por otro lado, José Antonio Planes en su estudio de la mujer en el cine español, clasifica a los personajes femeninos en los estereotipos nacionales que considera más recurrentes, como: "El ama de casa, la niña prodigio/cantante/folclórica, mujeres célebres y la religiosa" (2010, pp. 215-243).

A diferencia de estos autores, esta investigación ha optado por nombrar los arquetipos según las características que más los definen, por lo que su descripción no está explícitamente detallada en este apartado. En base a este marco teórico, esta investigación ha establecido la siguiente clasificación de los personajes femeninos interpretados por las actrices premiadas con un premio Goya en el período indicado, según el arquetipo que representan:

Tabla 1. Actrices premiadas entre 2010 y 2020 y arquetipo que representa

\begin{tabular}{|c|c|c|c|c|c|c|}
\hline Edición & Protagonista & Arquetipo & Reparto & Arquetipo & Revelación & Arquetipo \\
\hline \multirow{2}{*}{2020} & Belén Cuesta & \multirow{2}{*}{ Sufridora } & $\begin{array}{l}\text { Julieta } \\
\text { Serrano }\end{array}$ & \multirow{2}{*}{ Madre } & $\begin{array}{l}\text { Benedicta } \\
\text { Sánchez }\end{array}$ & \multirow{2}{*}{ Madre } \\
\hline & $\begin{array}{l}\text { La Trinchera } \\
\text { infinita }\end{array}$ & & $\begin{array}{l}\text { Dolor y } \\
\text { Gloria }\end{array}$ & & Lo que arde & \\
\hline \multirow{2}{*}{2019} & Susi Sanchez & \multirow{2}{*}{ Madre } & $\begin{array}{l}\text { Carolina } \\
\text { Yuste }\end{array}$ & \multirow{2}{*}{$\begin{array}{c}\text { Mujer que } \\
\text { apoya una } \\
\text { causa } \\
\text { noble (a } \\
\text { mujeres) }\end{array}$} & Eva Llorach & $\begin{array}{c}\text { Mujer que } \\
\text { apoya una } \\
\text { causa } \\
\text { noble }\end{array}$ \\
\hline & $\begin{array}{c}\text { La } \\
\text { enfermedad } \\
\text { del domingo }\end{array}$ & & $\begin{array}{l}\text { Carmen } \\
\text { y Lola }\end{array}$ & & $\begin{array}{l}\text { Quién te } \\
\text { cantará }\end{array}$ & $\begin{array}{c}(\mathrm{a} \\
\text { mujeres) }\end{array}$ \\
\hline 2018 & Nathalie Poza & $\begin{array}{c}\text { Luchador } \\
\text { a }\end{array}$ & $\begin{array}{l}\text { Adelfa } \\
\text { Calvo }\end{array}$ & Luchadora & Bruna Cusí & Madre \\
\hline
\end{tabular}


REIVINDICACIÓN DE LAS REPRESENTACIONES FEMENINAS EN EL AUDIOVISUAL ESPAÑOL: ESTUDIO DE UNA DÉCADA DE ARQUETIPOS DE MUJERES EN LOS PREMIOS GOYA

\begin{tabular}{|c|c|c|c|c|c|c|}
\hline & $\begin{array}{l}\text { No sé decir } \\
\text { adiós }\end{array}$ & & El autor & & Estiu 1993 & \\
\hline \multirow[b]{2}{*}{2017} & Emma Suárez & \multirow[b]{2}{*}{ Madre } & $\begin{array}{l}\text { Emma } \\
\text { Suárez }\end{array}$ & \multirow[b]{2}{*}{ Madre } & $\begin{array}{c}\text { Anna } \\
\text { Castillo }\end{array}$ & \multirow[b]{2}{*}{ Luchadora } \\
\hline & Julieta & & $\begin{array}{c}\text { La } \\
\text { próxima } \\
\text { piel }\end{array}$ & & El olivo & \\
\hline \multirow{2}{*}{2016} & $\begin{array}{c}\text { Natalia de } \\
\text { Molina } \\
\end{array}$ & \multirow{2}{*}{ Madre } & $\begin{array}{c}\text { Luisa } \\
\text { Gavasa }\end{array}$ & \multirow{2}{*}{ Madre } & $\begin{array}{c}\text { Irene } \\
\text { Escolar }\end{array}$ & \multirow{2}{*}{ Luchadora } \\
\hline & $\begin{array}{l}\text { Techo y } \\
\text { comida }\end{array}$ & & La novia & & $\begin{array}{l}\text { Un otoño } \\
\text { sin Berlín }\end{array}$ & \\
\hline \multirow[b]{2}{*}{2015} & Bárbara Lenie & \multirow[b]{2}{*}{ Demente } & $\begin{array}{c}\text { Carmen } \\
\text { Machi }\end{array}$ & \multirow[b]{2}{*}{ Madre } & $\begin{array}{l}\text { Nerea } \\
\text { Barros }\end{array}$ & \multirow[b]{2}{*}{ Madre } \\
\hline & Magical Girl & & $\begin{array}{c}\text { Ocho } \\
\text { apellido } \\
\text { s vascos }\end{array}$ & & $\begin{array}{l}\text { La isla } \\
\text { mínima }\end{array}$ & \\
\hline \multirow[b]{2}{*}{2014} & $\begin{array}{l}\text { Marian } \\
\text { Álvarez } \\
\end{array}$ & \multirow[b]{2}{*}{$\begin{array}{c}\text { Cuidador } \\
\text { a }\end{array}$} & $\begin{array}{l}\text { Terele } \\
\text { Pávez }\end{array}$ & \multirow[b]{2}{*}{ Bruja } & $\begin{array}{c}\text { Natalia de } \\
\text { Molina }\end{array}$ & \multirow[b]{2}{*}{ Luchadora } \\
\hline & La herida & & $\begin{array}{c}\text { Las } \\
\text { brujas } \\
\text { de } \\
\text { Zugarra } \\
\text { murdi }\end{array}$ & & $\begin{array}{l}\text { Vivir es fácil } \\
\text { con los ojos } \\
\text { cerrados }\end{array}$ & \\
\hline \multirow[b]{2}{*}{2013} & Maribel Verdú & \multirow[b]{2}{*}{ Bruja } & $\begin{array}{c}\text { Candela } \\
\text { Peña }\end{array}$ & \multirow{2}{*}{$\begin{array}{l}\text { Objeto de } \\
\text { seducción } \\
\text { de un } \\
\text { hombre }\end{array}$} & $\begin{array}{c}\text { Macarena } \\
\text { García }\end{array}$ & \multirow[b]{2}{*}{ Luchadora } \\
\hline & Blancanieves & & $\begin{array}{c}\text { Una } \\
\text { pistola } \\
\text { en cada } \\
\text { mano }\end{array}$ & & $\begin{array}{c}\text { Blancanieve } \\
s\end{array}$ & \\
\hline \multirow{2}{*}{2012} & Elena Anaya & \multirow{2}{*}{ Sufridora } & $\begin{array}{c}\text { Ana } \\
\text { Wagene } \\
r\end{array}$ & \multirow{2}{*}{ Cuidadora } & María León & \multirow{2}{*}{ Luchadora } \\
\hline & $\begin{array}{c}\text { La piel que } \\
\text { habito }\end{array}$ & & $\begin{array}{c}\text { La voz } \\
\text { dormida }\end{array}$ & & $\begin{array}{c}\text { La voz } \\
\text { dormida }\end{array}$ & \\
\hline \multirow{2}{*}{2011} & Nora Navas & \multirow{2}{*}{ Madre } & $\begin{array}{c}\text { Laia } \\
\text { Marull }\end{array}$ & \multirow{2}{*}{ Demente } & $\begin{array}{l}\text { Marina } \\
\text { Comas }\end{array}$ & \multirow{2}{*}{ Amiga de } \\
\hline & Pa negre & & $\begin{array}{c}P a \\
\text { negre }\end{array}$ & & Pa negre & \\
\hline \multirow{2}{*}{2010} & Lola Dueñas & \multirow{2}{*}{ Demente } & $\begin{array}{l}\text { Marta } \\
\text { Etura } \\
\end{array}$ & \multirow{2}{*}{ Mujer de } & $\begin{array}{l}\text { Soledad } \\
\text { Villamil } \\
\end{array}$ & \multirow{2}{*}{ Luchadora } \\
\hline & Yo, también & & $\begin{array}{c}\text { Celda } \\
211\end{array}$ & & $\begin{array}{l}\text { El secreto } \\
\text { de tus ojos }\end{array}$ & \\
\hline
\end{tabular}

Fuente: Elaboración propia (Academia de Cine, 2010-2020)

Una dificultad reseñable a la que se ha enfrentado este estudio para establecer los arquetipos de forma diferenciada, es la contaminación de características estereotipadas de algunas categorías proveniente de otras. Los arquetipos están compuestos por características mixtas procedentes de otros personajes también 
estereotipados. Para determinarlos ha prevalecido el criterio de las investigadoras analizando las cualidades que destacaban por encima de las otras en cada personaje. Los casos más representativos son los de "la cuidadora"," la sufridora "y la "luchadora ", cuyas características son atribuibles también a los personajes de madre en gran medida. De hecho, la categoría de "la cuidadora "no ha resultado representada en los índices en un tanto por ciento más elevado porque se ha separado de la categoría "madre ". Pedro Almodóvar demuestra en Dolor y Gloria (2020) cómo se suma a esta forma de diseñar los personajes que son madres, y hasta sus últimos días el rol que interpreta Julieta Serrano le pide explicaciones a su hijo sobre su comportamiento, de una forma sobreprotectora: "la noche antes de rodar la secuencia de Julieta y Antonio en la que ella le pide explicaciones se me ocurrió esta misma secuencia. Quería dar más profundidad y protagonismo al personaje de la madre "(Comunicación personal, 26 de enero de 2020). Es otro ejemplo más de cómo puede adquirir características un personaje sin estar escrito o planificado anteriormente, tal y como se recoge en las declaraciones de Adelfa Calvo. En el caso de Pedro Almodóvar estas características que añade al personaje de Serrano reafirman más el arquetipo de "madre cuidadora ", confirmando que este estereotipo se encuentra contaminado de forma reseñable por otros como el de mujer "cuidadora ".

En la categoría "mujer/amiga de", que indica la existencia de un personaje femenino supeditado a la de otro masculino, cabe que señalar que no se han contabilizado los arquetipos de "madre "que evidentemente son roles que existen porque los personajes de hijos tienen su espacio en la ficción. En la categoría de "demente "existe un personaje contaminado de forma reseñable por los arquetipos de "mujer de " $y$ " sufridora". El arquetipo de mujer cuidadora que interpreta Ana Wagener en La voz dormida (Benito Zambrano, 2012) se encuentra contaminado por el de la luchadora, y bien podría considerarse el rol de una madre de las presas. Wagener da vida a una de las carcelarias que intenta ayudar a las presas políticas a sobrellevar su cautiverio, por lo que es un personaje en el que confluyen características de varios arquetipos, algo que se repite en la muestra analizada.

La mujer "objeto de seducción de un hombre" también se encuentra presente en la muestra representada por Candela Peña en una de las varias tramas que se cruzan en el filme (Cesc Gay, 2012). Eso nos acerca a los estudios de Mulvey, que afirma que "en un mundo ordenado por el desequilibrio sexual, el placer de mirar se ha escindido entre activo/masculino y pasivo/femenino" (1999, pp. 808-809).

En esta última década de producción cinematográfica en España, la representación de arquetipos de mujeres reflejados en los personajes de aquellas actrices cuyas interpretaciones han sido más valoradas por la Academia, se ha distribuido según indican las siguientes gráficas. 


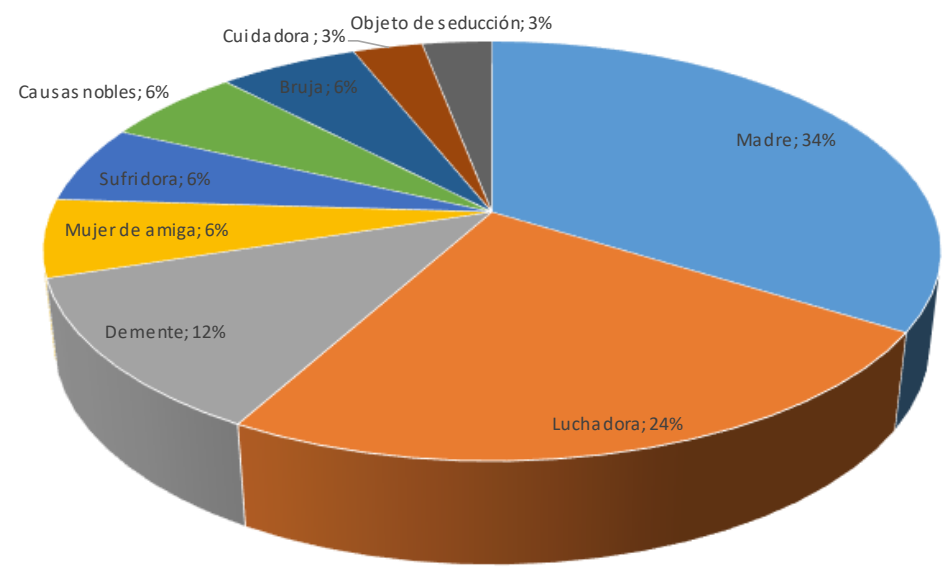

Grafico 1. Porcentaje de arquetipos femeninos representados por las actrices premiadas con un Goya entre 2010 y 2020

Fuente: Elaboración propia

De todos estos arquetipos el de madre es el más repetido, recogiendo el legado de los estereotipos que identifica Virginia Guarinós en su estudio (2008, pp.115-118). La madre estereotipada puede clasificarse a su vez en otros subgrupos con características de arquetipos de mujer que no son progenitoras y están representadas en el cine de la muestra que estudia esta investigación. Estos "sub-arquetipos " del personaje de madre se han representado distribuidos de la siguiente forma:

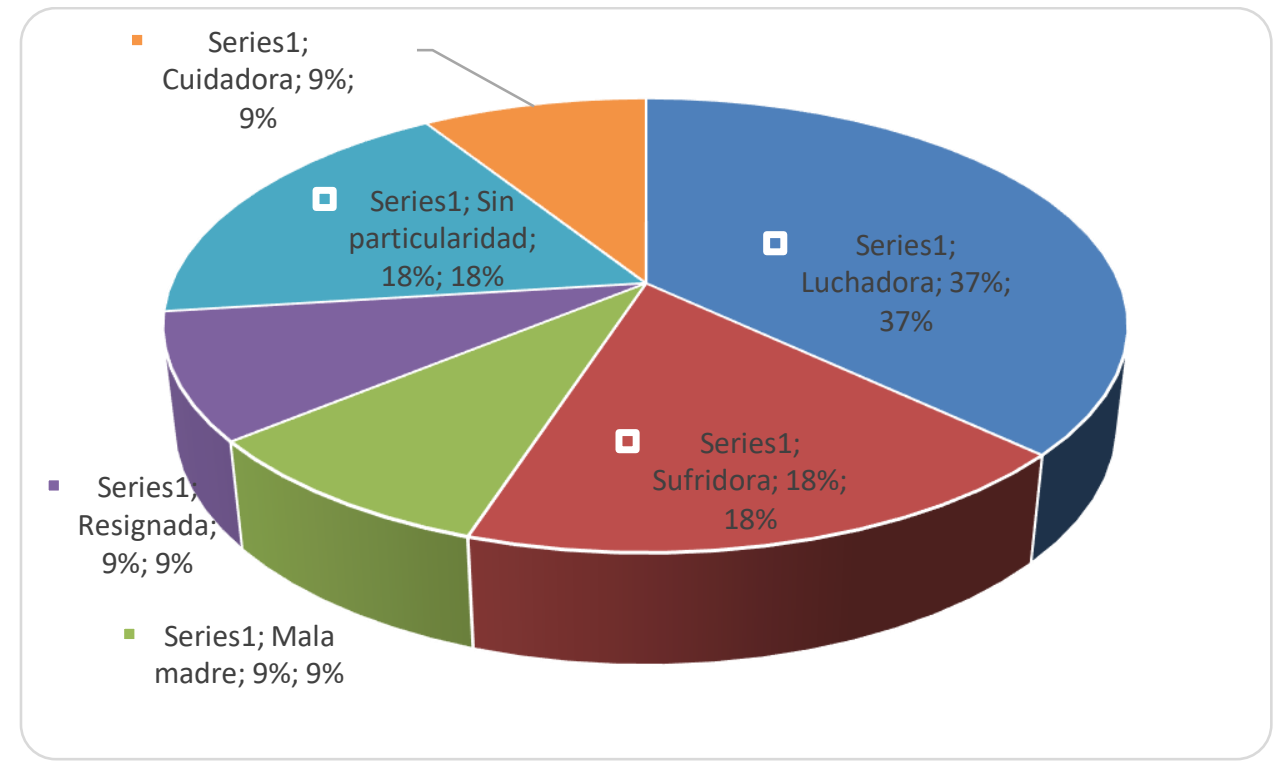

Gráfico 2. Porcentaje de las tipologías de madres representadas por las actrices premiadas con un Goya entre 2010 y 2020

Fuente: Elaboración propia

Tras el análisis de contenido de las revistas y suplementos se ha observado que las actrices que mayor repercusión mediática han obtenido son las galardonadas por 
interpretar personajes de "madre" y "mujer luchadora". Es un dato reseñable que esos porcentajes de representatividad se encuentren aumentados con respecto a los resultantes del análisis de personajes cuyas interpretaciones han sido galardonadas. También es destacable que repetitivos arquetipos femeninos como el de "cuidadora" no aparezca representado en medios impresos. Tampoco aparece el arquetipo de "demente "detalle que explicaría la invisibilidad de problemas reales que padecen las mujeres pero que sin embargo socialmente se esconden.

\section{Arquetipos con mayor repercusión en medios impresos femeninos}

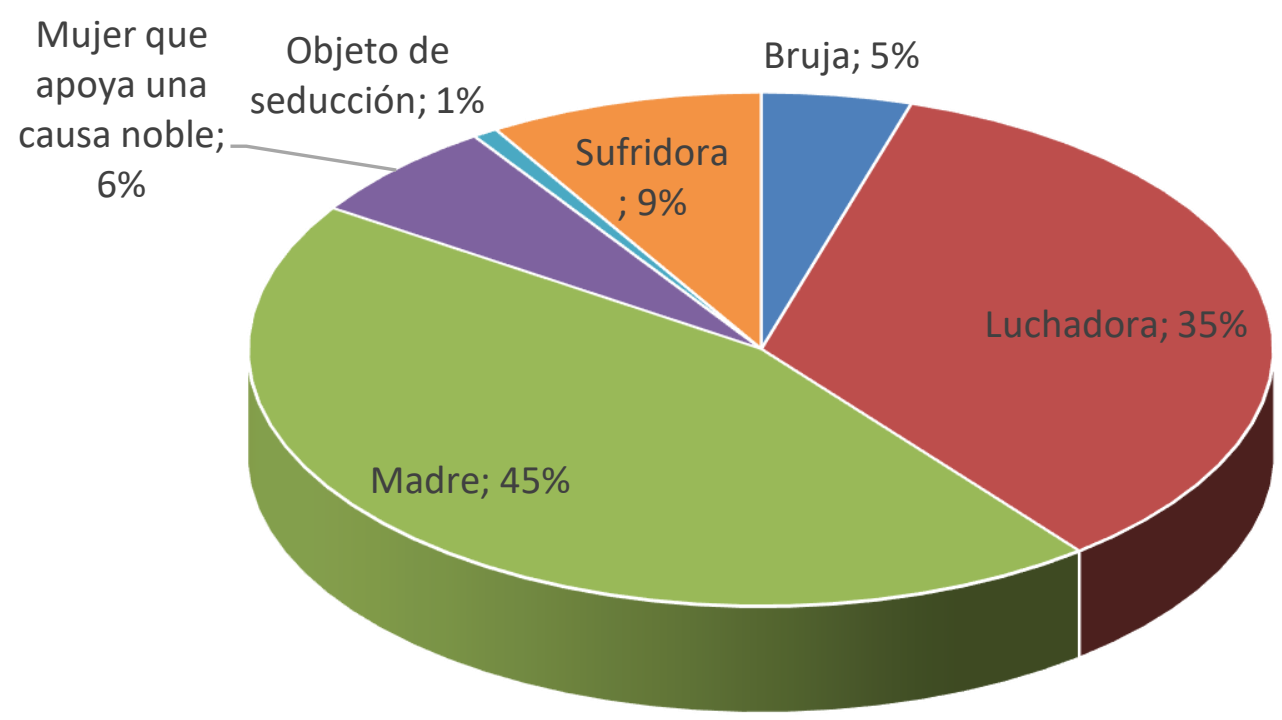

Gráfico 3. Porcentaje de arquetipos con mayor repercusión en revistas para la mujer Fuente: Elaboración propia

\section{CONCLUSIONES}

Tras el análisis efectuado, esta investigación ha demostrado que en la segunda década del siglo XXI sigue existiendo una reseñable discriminación sexista en la industria del cine en España, relegando a las actrices a una situación de marginación con respecto a la de los actores para acceder a trabajos y mantener su actividad laboral en el tiempo. Esta desigualdad se ha demostrado que incluso ha afectado a las actrices mediáticamente más célebres del sector galardonadas con un Premio Goya en el período de tiempo analizado, de 2010 a 2020, por lo que a todas aquellas que no han obtenido ninguna mención de honor obviamente esta discriminación les ha afectado de una forma más agresiva. La dificultad de las actrices para acceder al mercado laboral del sector cinematográfico en España se produce por diversas causas, algunas de las cuáles se arrastran desde el pasado:

1. El diseño de personajes para mujeres se hace de forma estereotipada. En esta última década los arquetipos interpretados por las actrices más valoradas por la Academia han sido principalmente madres cuya dedicación plena a los hijos 
no es valorada como tal, ya que se da por hecho que deben cumplir a la perfección su función como protectoras de su descendencia tengan la edad que tengan. Este es el caso del personaje de Julieta Serrano en Dolor y Gloria (Almodóvar, 2020), que hasta en sus últimos días pide a su hijo rendir cuentas de su comportamiento en un acto protector para que no baje la guardia y así provocar una extensión de sus cuidados cuando ella no esté. Hoy día nuestra sociedad y el mercado laboral sigue sufriendo el lastre a causa adoctrinamiento ideológico de la dictadura, el nacionalcatolicismo que para repoblar España educó a la población para que cargara el peso del cuidado de los hijos y del hogar en la mujer como si fuese una obligación moral y económica para el bien común, en pro de las necesidades de la patria (De Riquer, 2013, p. 293). También destacan cuantitativamente personajes de mujeres luchadoras, que a lo largo de los filmes no llegan a considerarse héroes a pesar de llevar a cabo hazañas. Es significativo la inclusión en esta muestra del personaje de bruja que odia a los hombres interpretado por Terele Pávez en Las brujas de Zugarramurdi (Álex de la Iglesia, 2011), entendiéndose por extensión que el hecho de sentir esta animadversión por el género masculino ya convierte a una mujer en un ser despreciable, sin cuestionar si los sujetos detestados por ella son merecedores de tal sentimiento. Los otros arquetipos de la muestra, como la mujer demente, la mujer de/amiga de, la sufridora, la defensora de causas nobles (y de otras mujeres) o la cuidadora se restringen a una concepción de personajes pobre. La heroicidad y la puesta en valor del trabajo como madres, cuidadoras y luchadoras son procesos que no se relacionan con sus personajes de forma manifiesta o llamativa.

2. Diseñar los personajes femeninos de forma estereotipada resta riqueza narrativa a los roles de mujer, con lo cual se reducen, haciendo que el trabajo para las actrices disminuya con respecto al de los hombres.

3. Las revistas para mujeres de alta gama ayudan a perpetuar la discriminación machista de las actrices en el cine español, difundiendo su imagen de forma sesgada y desmejorada por las connotaciones patriarcales indicadas a lo largo de este trabajo.

4. Como señala la autora Lucía Tello, el diseño de personajes femeninos estereotipados deriva del más difícil acceso de las mujeres a dirigir largometrajes con respecto a los hombres. En su estudio de 2016 las cifras indican que: "Las mujeres otorgan el protagonismo a las mujeres de manera más habitual, alcanzando casi el $50 \%$ de las producciones realizadas por las directoras, frente al $80 \%$ del protagonismo masculino del que adolecen las películas dirigidas por varones" (Tello, 2016).

Como se demuestra en el apartado "Premios Goya y reivindicaciones: personajes para mujeres ", las actrices españolas sí han luchado en esta última década para reivindicar una situación de igualdad. Concretamente en los Premios Goya 2018, la actriz Adelfa Calvo confirma que alzaron la voz y realizaron acciones coordinadas por CIMA (Asociación de Mujeres Cineastas y de Medios Audiovisuales). También la intérprete confirma haber aportado algo importante a la lucha de los derechos fundamentales de las actrices, explicando cómo el personaje por el que recibe el Goya a Mejor Actriz de Reparto 2018 estaba escrito sin el trasfondo ni las cualidades que ella le dio convenciendo al director de El Autor (Martín-Cuenca, 2017) para que se cambiara lo que estaba escrito en el guión. Le dio hasta el nombre que no tenía en la separata. 
Sin embargo, como también señala ella misma en la entrevista concedida a esta investigación, se trata de algo aislado que depende de la capacidad intelectual y arrojo que una actriz en concreto tenga para llevar a cabo esta iniciativa individual, y de lo receptivo que esté el director del proyecto para permitir cambios (comunicación personal, 29 de octubre de 2020). Queda demostrado que las actrices españolas de la industria han luchado y reivindicado su derecho a la igualdad de forma individual o grupalmente organizadas incluso institucionalmente. A pesar de ello sus voces no se han tenido en cuenta para acabar con la opresión que llevan padeciendo más de un siglo. Por ello, como conclusión final, esta investigación manifiesta la necesidad imperiosa de que instituciones culturales y el Ministerio de Igualdad promuevan una ley que ayude a las actrices a remontar esta situación discriminatoria e injusta, ya que durante la dictadura se aprobó un decreto sexista cuyos efectos las sigue marginando en la actualidad de forma agresiva como profesionales y como mujeres.

\section{BIBLIOGRAFÍA}

Almansa-Martínez, A., Gómez de Travesedo-Rojas, R. (2017). El estereotipo de mujer en las revistas femeninas españolas de alta gama durante la crisis. Revista Latina de Comunicación Social, 72, 608 a 628.

Almodóvar, P. (2020, 26 enero). Comunicación personal.

Almodóvar, P. (Director). (2016). Julieta [Película]. El Deseo Producciones.

Almodóvar, P. (Director). (2019). Dolor y Gloria [Película]. El Deseo Producciones.

Almodóvar, P. (Diretor). (2011). La piel que habito [Película]. El Deseo, Blue Haze Entertainment, Canal+ España, TVE, Instituto de la Cinematografía y de las Artes Audiovisuales y FilmNation Entertainment.

Asociación para la Investigación de Medios de Comunicación, AIMC. (2020, 9 de diciembre). Entrega de resultados EGM $1^{\underline{a}}$ ola 2020. AIMC. https://reporting.aimc.es/index.html\#/main/cockpit

Bardin, L. (1991). Análisis de contenido. Vol. 89. Ediciones Akal.

Berger, P. (Director). (2012). Blancanieves [Película]. Arcadia Motions Pictures y Noodles Production

Bernárdez-Rodal, A. y Padilla-Castillo, G. (2018). Mujeres cineastas y mujeres representadas en el cine comercial español (2001-2016). Revista Latina de Comunicación Social, 73, 1247-1266.

Blanco García, A. I., \& Leoz, D. (2010). La persistencia de los estereotipos tradicionales de género en las revistas para mujeres adolescentes: Resistencias al cambio y propuestas de modificación. Ex ae quo, (22), 147-169. 
REIVINDICACIÓN DE LAS REPRESENTACIONES FEMENINAS EN EL AUDIOVISUAL ESPAÑOL: ESTUDIO DE UNA DÉCADA DE ARQUETIPOS DE MUJERES EN LOS PREMIOS GOYA

Bollaín, I. (Director). (2016). El olivo [Película]. Morena Films y The Match Factory Productions

Calvo, A. (2020, 29 octubre). Comunicación personal

Calvo, A. (2020, 30 octubre). Comunicación personal

Campanella, J. J. (Director). (2009). El secreto de sus ojos [Película]. Haddock Films, Tornasol Films, 100 Bares, Telefe, TVE y Canal+ 1

Castelló Martínez, A. y Jover Román, A. (2018). Televisión social y 'marketing' en tiempo real en retransmisiones televisivas de eventos mediáticos. El caso de los Premios Goya 2018. Trípodos, 43, 57-82.

Cristófol Rodríguez, C., \& Méndiz Noguero, A. (2010). Nuevas estrategias de creación de imagen en las marcas de moda: La hibridación de información y publicidad en los contenidos de las revistas femeninas. In Actas II Congreso Internacional Latina de Comunicación Social: La Comunicación Social, en estado crítico: entre el mercado y la comunicación para la libertad (p. 29). Sociedad Latina de Comunicación Social.

Cristófol-Rodríguez, C., \& Méndiz-Noguero, A. (2015). Análisis del brand placement en las revistas femeninas. Hibridación de discursos: informativo, publicitario y de la moda. Revista Mediterranea de Comunicación Social. 6(1), 7-25.

Cuenca, M. M. (Director). (2017). El autor [Película]. Icónica Producciones, Lazona Films y La Loma Blanca PC

De la Iglesia, A. (Director). (2013). Las brujas de Zugarramurdi [Película]. Enrique Cerezo P. C., La Ferme ! Productions

De Riquer, B. (2013). La dictadura de Franco, vol. I. Barcelona: Crítica - Marcial Pons.

Del Castillo, J. M. (Director). (2015) Techo y comida [Película]. Diversa Audiovisual

Díaz-Bravo, L., Torruco-García, U., Martínez-Hernández, M., \& Varela-Ruiz, M. (2013). La entrevista, recurso flexible y dinámico. Investigación en educación médica, 2(7), 162-167.

Echevarría, A. (Director). (2018). Carmen y Lola [Película]. Arantxa Echevarría y Pilar Sánchez

Ediciones anteriores. 2010-2020. https://www.premiosgoya.com/los-goya/que-son/

Escalera, L. (Director). (2017). No sé decir adiós [Película]. Lolita Films y White Leaf Producciones

Everly, K. (2016). Acercamientos feministas al cine español y latinoamericano: la mujer como producto y productora de imágenes. Hispanófila, 177,179-193. 
Franco García, F. (Director). (2013). La herida [Película]. Kowalski Films

Freixa Font, P. (2015). Reportajes especiales en los cibermedios. Análisis de diez años de Premios Goya y Oscar Awards en Elpais.com (2005-2014). El profesional de la información, 24(3), 291-300. https://doi.org/10.3145/epi.2015.may.09

Garaño, J., Arregi, A. y Goenaga, J. M. (Director). (2019). La trinchera infinita [Película]. Irusoin y Moriarti Productions

García, T., García, L., González, R., Carvalho, J., \& Catarreira, S. (2016). Revisión metodológica de la triangulación como estrategia de investigación. CIAIQ2016, 3.

Gay, C. (Director). (2012). Una pistola en cada mano [Película]. Impossible Films, TV3 y TVE.

Gordillo, I. (2010). La mujer "envejeciente": silencios, estereotipos y miradas en el cine de la primera década del siglo XXI. En P. Sangro y J.F. Plaza (eds), La representación de las mujeres en el cine y la televisión contemporáneo, (pp. 97117). Barcelona: Laertes.

Guarinos, V. (2008). Los medios de comunicación con mirada de género. En F. Loscertales y T. Núñez (eds.), Mujer y cine, (pp. 103-120). Sevilla: Instituto Andaluz de la Mujer.

Historia de las reivindicaciones en los Premios Goya. 2002-2014. Recuperado de https://www.premios-cine.com/goya/fotos/goya-2014/30/historia-reivindicacionespremios-goya.htm

Izaguirre, L. (Director). (2015). Un otoño sin Berlín [Película]. Gariza Produkzioak.

Jurado González, J. (2018). Mujer, roles de género y política de premios en el cine español (1940-1959). Investigaciones feministas, 9, 119-135.

Lacuesta, I. y Campo, I. (Director). (2016). La próxima piel [Película]. Bord Cadre Films, Corte y Confección de Películas, La Termita Films y Sentido Films.

Laxe, O. (Director). (2019). Lo que arde [Película]. Miramemira, Kowalski Films, Tarantula Luxembourg y 4 a 4 Productions.

Marrades, M. I. (1978). Feminismo, prensa y sociedad en España. Papers: revista de sociologia, 89-134.

Martín García, T. (2017) Los blogs de moda: nuevos preservadores de los estereotipos de género de las revistas femeninas. [Tesis]

Martínez Carazo, P. C. (2011). El método de estudio de caso Estrategia metodológica de la investigación científica. Revista científica Pensamiento y Gestión, 20. 
REIVINDICACIÓN DE LAS REPRESENTACIONES FEMENINAS EN EL AUDIOVISUAL ESPAÑOL: ESTUDIO DE UNA DÉCADA DE ARQUETIPOS DE MUJERES EN LOS PREMIOS GOYA

Martínez-Lázaro, E. (Director). (2014). Ocho apellidos vascos [Película]. Lazonafilms, Kowalski Films, Telecinco Cinema

Monzón, D. (Director). (2009). Celda 211 [Película]. Morena Films, Vaca Films y Telecinco Cinema.

Mulvey, L. (1999). Visual Pleasure and Narrative Cinema. En L. Braudy y M. Cohen (eds.), Film Theory and Criticism: Introductory Readings, (pp. 833-844). Nueva York: Oxford Up

Observaciones de Campo Goyas 2020

Ortiz, P. (Director). (2015). La novia [Película]. Get In The Picture Productions, Mantar Film, Televisión Española.

Pastor Gaspar, A. y Naharro, A. (Director). (2009). Yo, también [Película]. Alicia Produce y Promico Imagen.

Pérez Granado, V. (2006). 20 años de Goyas al cine español. Madrid: Aguilar.

Planes, J. A. (2010). La mujer en el cine español. En E. Pérez Romero (ed.), Estereotipos "nacionales", (pp. 215-243). Madrid: Arkadin

Rodríguez Sánchez, J. (2012). La mujer en el cine español. Madrid: Arkadin

Rodríguez, A. (Director). (2014). La isla mínima [Película]. Atípica Films, Sacromonte Films y Antena 3 Films.

Salazar, R. (Director). (2018). La enfermedad del domingo [Película]. Zeta Cinema y On Cimena.

Sánchez Hernández, M. (2010). Evolución de las publicaciones femeninas en España. Localización y análisis. Documentación de las Ciencias de la Información, 32, 217244.

Sánchez Rodríguez, V. (2018). Perfiles profesionales de las actrices del cine español del Desarrollismo (1959-1975). Vivat Academia, 142, 19-37.

Sánchez Rodríguez, V. (2013). La Banda Sonora Musical en el cine español y su empleo en la configuración de tipologías de mujer (1960-1969). Ediciones Universidad de Salamanca, Salamanca

Serrano, J. (2020, 26 enero). Comunicación personal

Sevilla, I. (2020, 30 octubre). Comunicación personal

Simón, C. (Director). (2017). Estiu 1993 [Película]. Inicia Films y Avalon PC 
Taylor, S. J., \& Bogdan, R. (2008). La entrevista en profundidad. Métodos cuantitativos aplicados, 2, 194-216.

Tello Díaz, L. (2016). La "mirada femenina": estereotipos y roles de género en el cine español (1918-2015). Ámbitos. Revista Internacional de Comunicación, 34, 11391979.

Trueba, D. (Director). (2013). Vivir es fácil con los ojos cerrados [Película]. Paco León PC, Canal + y TVE

Vermut, C. (Director). (2014). Magical Girl [Película]. Aquí y Allí Films

Vermut, C. (Director). (2018). Quién te cantará [Película]. Apaches Entertainment

Villaronga, A. (Director). (2010). Pa Negre [Película]. Mass d'Or PC y Televisió de Catalunya

Vizcaíno-Laorga, R., Montes Vozmediano, M. y de la Torre, P. (2017). Tocando la realidad en la producción de contenidos informativos, rutinas profesionales y participación en entornos digitales. Prisma Social: revista de investigación social, 18, 192-225.

Zambrano, B. (Director). (2011). La voz dormida [Película]. Warner Bros

\section{AUTORES}

\section{Paula Meliveo Nogues}

Doctora Cum Laude en Comunicación Audiovisual por la URJC de Madrid. Experiencia profesional en televisión, radio y cine (Antena 3 informativos, programas de actualidad y entretenimiento en Canal Sur, TVE, La Sexta, Europa FM, etc). Redactora, guionista, presentadora, reportera, actriz, y periodista en Depto. de Comunicación de festivales de cine. También ha trabajado para La Academia de Cine en la retransmisión de Premios Goya, presentando y entregando el Goya a la Mejor Película Documental 2020, con un impacto mediático de 9 millones de espectadores en el peak time. Ha impartido docencia en la Universidad de Málaga en Comunicación Audiovisual y Publicidad. Su labor investigadora se desarrolla desde 1998 hasta la actualidad.

paulameliveo@uma.es

ORCID: https://orcid.org/0000-0002-2680-8564

Google Schoolar: https://scholar.google.com/citations?user=pwm7itkAAAAJ\&hl=es

\section{Carmen Cristófol-Rodríguez}

Doctora en Comunicación y Licenciada en Publicidad y Relaciones Públicas (UMA). Participa como IP en Proyectos de Innovación Docente, como evaluadora en revistas de reconocido prestigio, y como miembro de tribunales de tesis y trabajos fin de máster. Editora de sección de Revista Mediterránea de Comunicación, investigadora en los grupos COMPUBES (Comunicación y Públicos Específicos) y IICCXXI (Industrias Culturales Hoy), ambos de la Universidad de Alicante. Es socia de la AEIC 
REIVINDICACIÓN DE LAS REPRESENTACIONES FEMENINAS EN EL AUDIOVISUAL ESPAÑOL: ESTUDIO DE UNA DÉCADA DE ARQUETIPOS DE MUJERES EN LOS PREMIOS GOYA

(sección 10) y AIRRPP. Forma parte del Programa de Doctorado Interuniversitario. Tiene experiencia docente en universidades públicas y privadas y en docencia virtual y presencial. Durante 17 años ha compaginado su labor docente e investigadora con su faceta como profesional de los medios de comunicación. Cuenta con un sexenio de investigación.

carcrir@uma.es

ORCID: https://orcid.org/0000-0001-9766-6500

Google Schoolar: https://scholar.google.es/citations?user=FAOooOwAAAAJ\&hl=es Publons: https://publons.com/researcher/3485105/carmen-cristofol/ 